\title{
Monoclonality in B cell lymphoma detected in paraffin wax embedded sections using the polymerase chain reaction
}

\author{
J H Wan, K J Trainor, M J Brisco, A A Morley
}

\begin{abstract}
The polymerase chain reaction (PCR) was used to develop a simple technique for detecting monoclonality at the DNA level in $B$ lymphocyte populations in formalin fixed, paraffin wax embedded material. Sections were dewaxed and dehydrated, and the DNA was extracted by boiling in water for 45 minutes. A semi-nested PCR was performed to amplify the V-D-J region of the immunoglobulin heavy chain gene. The product was electrophoresed and viewed under ultraviolet light after ethidium bromide staining. Specimens from $26 \mathrm{~B}$ cell lymphomas produced a monoclonal band in 24 cases and no amplification in two cases; monoclonality was specific for this disorder. Specimens from seven $T$ cell lymphomas produced no amplification; specimens from nine reactive nodes produced a broad smear of polyclonal material; and specimens from 12 cases of carcinoma produced either no amplification or polyclonal material.

As detection of monoclonality is strongly suggestive of neoplastic disease, this technique is likely to be of value in routine diagnosis, because of its speed, simplicity, and applicability to fixed, embedded material.
\end{abstract}

Diagnosis and classification of malignant lymphoma is still a challenge, in part due to the limitations and ambiguities of morphology and immunophenotyping. Analysis of the immunoglobulin and $T$ cell receptor genes by Southern blotting to show monoclonality has helped in the distinction between neoplastic and reactive disorders, ${ }^{1}$ and to a lesser extent, in the assignment of lineage. Southern blotting, however, is of limited value for routine diagnostic work because it is slow and complex, requires the use of radioactive isotopes and a large amount (1-5 $\mu \mathrm{g})$ of DNA, and is not well suited to the study of fixed, embedded material owing to degradation of DNA.

Trainor et al reported a technique based on the polymerase chain reaction (PCR) for rapid diagnosis of $\mathbf{B}$ lymphocyte neoplasms in frozen or fresh samples of blood, bone marrow, or lymph node. ${ }^{2}$ In this paper we extend this technique to the detection of neoplastic populations in paraffin wax embedded sections and show that it is possible to distin- guish B cell lymphoma from other neoplastic and non-neoplastic conditions.

\section{Methods}

Paraffin wax embedded, formalin fixed tissue sections were obtained from the Department of Histopathology, Flinders Medical Centre, and included lymph node tissue from 26 patients with B cell non-Hodgkin's lymphoma (B-NHL), seven patients with $\mathrm{T}$ cell nonHodgkin's lymphoma (T-NHL), nine patients with reactive lymph node enlargement, and other tissues from 12 patients with nonlymphocytic neoplasms (pulmonary adenoma, carcinoma from oesophagus, stomach, colon, breast, skin, prostate).

All of the tissue samples had previously been studied and classified as B or T NHL, reactive tissue, or carcinoma, by routine histopathology, immunohistochemistry, and, for all lymphomas, by Southern blotting of the immunoglobulin and $\mathrm{T}$ cell receptor genes. ${ }^{3}$

EXTRACTION OF DNA FROM TISSUE SECTIONS Two slices, $10 \mu \mathrm{m}$ thick, were cut from tissues embedded in paraffin wax blocks and placed in screw-cap Eppendorf tubes. Xylene $(800 \mu \mathrm{l})$ was added to dissolve the paraffin. After brief vortexing samples were left for five minutes, then centrifuged in an MSE MicroCentaur at $13500 \mathrm{rpm}$ for five minutes. The supernatant was removed using a fresh Pasteur pipette for each sample to avoid crosscontamination, and $800 \mu \mathrm{l}$ ethanol were added. After vortexing for 10-20 seconds and centrifuging for another five minutes the ethanol was pipetted off. This ethanol washing procedure was repeated once more. The samples were dried under vacuum for 45 minutes. Sterile water was added (200-400 $\mu$, according to the amount of cellular material present), and the samples were placed in a boiling water bath for 45 minutes. The supernatant was used as the DNA source for PCR amplification. Two or more DNA samples were prepared and tested from each tissue block.

\section{PRIMERS FOR PCR}

The primers used for the Joining (L) and $3^{\prime}$ end of the Variable (V) segments of the human immunoglobulin heavy chain genes ${ }^{24}$ were synthesised on an Applied Biosystems 381A DNA synthesiser and their sequences were as follows. 


Immunoglobulin
heavy chain gene
length varies between different genes

Figure 1 Diagram to show the human immunoglobulin heavy chain gene and the location of the PCR primers: Fr $3 A, L J H$, and VLJH and the sites where various numbers of nucleotides are added at random during $B$ lymphocyte differentiation. $V, D$, $J$, and $C$ show the Variable, Diversity, Joining and Constant segments of the gene.

For the third framework region (at the $3^{\prime}$ end of $\mathrm{V}$ ):

$$
\begin{aligned}
& \text { Fr3A - - 5' ACACG GC [C/T] [G/C] T } \\
& \text { GTATT ACTGT 3' }
\end{aligned}
$$

For the J region:

$$
\begin{aligned}
& \text { LJH - - 5' TGAGG AGACG GT GACC } \\
& \text { 3', or } \\
& \text { VLJH - - GTGAC CAGGG T [A/G/C/T] } \\
& \text { CCT TGGCC CCAG 3' }
\end{aligned}
$$

Fr3A is based on a consensus sequence from 17 human V-segments, ${ }^{5}$ while LJH and VLJH are based on a consensus from the six J regions. ${ }^{6}$ Use of these primers would be expected to generate a fragment of about 100 120 kilo base pairs in length (fig 1). The binding site for the VLJH primer is $5^{\prime}$ compared with that for the $\mathrm{LJH}$ primer.

\section{POLYMERASE CHAIN REACTION TECHNIQUE}

The PCR was performed in a Perkin-ElmerCetus Thermal Cycler. The reaction mix $(25 \mu \mathrm{l})$ contained $0.125 \mu \mathrm{g}$ of each primer, $1 \mathrm{mM}$ each of deoxyadenosine, deoxycytidine, deoxyguanosine, and thymidine triphosphate, $10 \% \mathrm{v} / \mathrm{v}$ dimethyl sulphoxide, $170 \mu \mathrm{g} / \mathrm{ml}$ bovine serum albumin (Sigma), $200 \mu \mathrm{g} / \mathrm{ml}$ gelatin, $16.6 \mathrm{mM}$ ammonium sulphate, $4.5 \mathrm{mM}$ magnesium chloride, $10 \mathrm{mM} \beta$ mercaptoethanol and $67 \mathrm{mM}$ TRIS-HCl (pH 8.8 at $25^{\circ} \mathrm{C}$ ), 0.2 units of $\mathrm{Taq}$ polymerase (Amplitaq: Cetus), and a template. Each reaction mix was overlaid with $50 \mu \mathrm{l}$ of light mineral oil (Sigma).

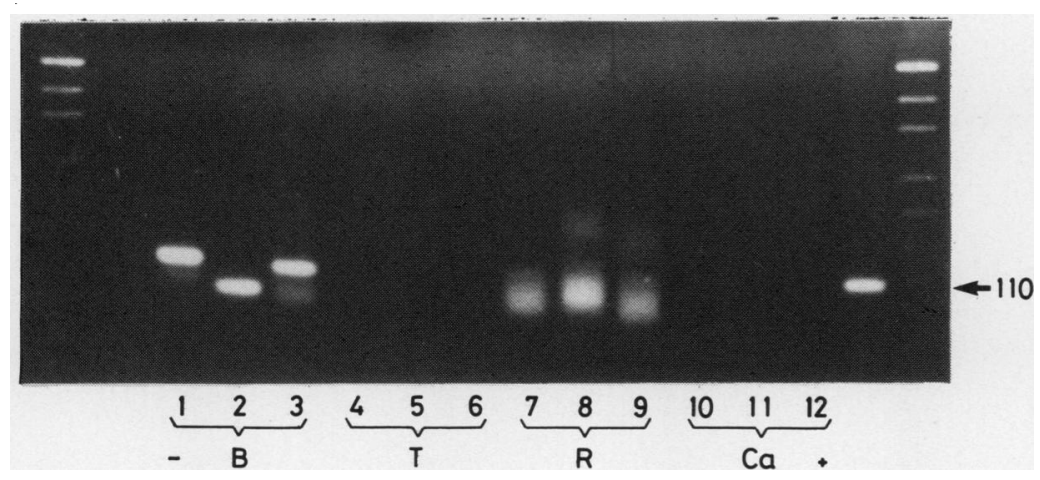

Figure 2 DNA amplified from material from paraffin wax embedded tissue sections to show detection of $B$ cell non-Hodgkin's lymphoma ( $B$ cell NHL), immunologically reactive tissue, and other neoplasms. The DNAs used for amplification were from $B$ cell NHL (tracks 1-3); T cell NHL (tracks 4-6); non-neoplastic immunologically reactive lymph node (tracks 7-9); non-lymphocytic carcinomas (tracks 10-12); pre-B lymphocytic cell line Nalm 6 (track labelled " $+")$. Also shown are a PCR reaction without DNA template (track labelled" "_") and molecular weight markers (the two outer tracks), with the sizes in base pairs of the bands shown to the right of the figure.
Samples were scored for the presence of a discrete monoclonal band as exemplified in fig 2 , tracks $1-3$.

A PCR cycle consisted of annealing for two minutes at $60^{\circ} \mathrm{C}$, extension for two minutes at $72^{\circ} \mathrm{C}$, and denaturation for two minutes at $94^{\circ} \mathrm{C}$. A semi-nested PCR was performed: a first round of 30 cycles with primers FR3A and $\mathrm{LJH}$ and $10 \mu \mathrm{l}$ of the boiled cellular extract as template; and a second round of 20 cycles with FR3A and VLJH, with $10 \mu \mathrm{l}$ of a 1 in 1000 dilution of the first round PCR as template. Before each round the PCR reaction was heated to $94^{\circ} \mathrm{C}$ for four minutes, and after each round a final extension step of six minutes at $72^{\circ} \mathrm{C}$ was performed. Each experiment also contained a tube without DNA template (as a negative control), and a tube whose template was DNA from pre-B lymphocyte line Nalm 6, which has its immunological genes rearranged (as a positive control). PCR amplified material $(5 \mu \mathrm{l})$ was electrophoresed in $2 \%$ agarose gels in TBE buffer $(89 \mathrm{mM}$ TRIS- $\mathrm{HCl}, 89 \mathrm{mM}$ boric acid, $2 \mathrm{mM}$ ethylene diamise $\mathbf{N}, \mathbf{N}, \mathbf{N}^{\prime}, \mathbf{N}^{\prime}$-tetra acetic acid) at 100 volts for 90 minutes and the DNA was visualised under short wavelength ultraviolet light after ethidium bromide staining of the gel.

\section{Results}

Figure 2 shows typical examples of the amplified DNA. Tracks 1-3 show the discrete monoclonal band (100-120 base pairs long) of amplified DNA observed in three cases of BNHL; tracks 4-6 show failure of amplification observed in three cases of T-NHL; tracks 7-9 show the broad smear of polyclonal amplified DNA observed in three cases of reactive lymphadenopathy; and tracks 10-12 show failure of amplification in three cases of carcinoma. The results of all experiments, summarised in the table, show that the detection of one or two discrete bands was absolutely specific for BNHL, with a sensitivity of $92 \%$. A diffuse polyclonal smear was seen in all cases of reactive nodes. T-NHL and carcinomas usually gave no amplification but polyclonal material was observed in several cases. The two cases of B-NHL which produced no amplified product were consistently negative on repeated testing.

\section{Discussion}

The PCR technique for detection of monoclonality, recently described by Trainor et $a l,{ }^{2}$ is based on the events which occur during immunoglobulin heavy chain gene 
rearrangement. In the germline state (and therefore in all cells except B lineage lymphocytes) the $\mathrm{V}$ and $\mathrm{J}$ segments of the gene are separated by several thousand bases of DNA, and the polymerase chain reaction, which uses primers binding to these regions, cannot take place. During the differentiation of B lymphocytes, however, a $\mathrm{V}$ and a $\mathrm{J}$ segment are brought close to each other. ${ }^{7}$ The polymerase chain reaction can generate a DNA fragment of $100-120$ base pairs which is readily detectable by electrophoresis on an agarose gel. The properties of the amplified product permit the ready distinction of a monoclonal population of neoplastic B lymphoid cells from a polyclonal population of non-neoplastic B lymphoid cells. During differentiation, varying numbers of nucleotides are added at random between the $\mathrm{V}, \mathrm{D}$, and $\mathrm{J}$ segments (fig 1 ). ${ }^{7}$ The two primers bind to fixed portions of the framework 3 , and J regions of the immunoglobulin genes and therefore different $\mathbf{B}$ cell clones, which have different rearrangements of their immunoglobulin genes, will give rise to amplified segments of different sizes. A monoclonal B lymphocyte population will therefore be characterised by amplified DNA of a single size, whereas a polyclonal B-lymphocyte population will be characterised by amplified DNA of a range of sizes.

The results in this study of fixed tissue compare well with those of Trainor $e t a l,{ }^{2}$ who used fresh or frozen tissue samples. Monoclonality was detected in $92 \%$ of cases of B-NHL and was specific for this disorder. As detection of monoclonality is strongly suggestive of neoplastic disease, the present technique is likely to be of value in routine diagnosis, owing to its speed, simplicity, and applicability to fixed, embedded material. It will also permit the retrospective study of large numbers of patients. The nested primer techique used in this study is helpful for small amounts of starting material. It is more sensitive and specific than the single round approach originally described by Trainor et al. ${ }^{2}$
In this study two of the 26 cases of B-NHL did not give a monoclonal band despite the detection in all of a monoclonal gene rearrangement by Southern blotting. This phenomenon has been noted before ${ }^{2}$ and possible explanations in these two patients are (1) atypical rearrangement, such as inversion of the immunoglobulin genes, which seems most likely, or (2) a false assignment of lineage by Southern blotting of the immunoglobulin and $T$ cell receptor genes. The Southern blotting method detects rearrangement of the immunoglobulin of T-cell receptor gene, irrespective of the final arrangement of the gene, ${ }^{1}$ whereas the PCR technique detects only V-D-J rearrangements which are in the correct orientation. Thus occasional cases in which monoclonal gene rearrangement can be detected by Southern blotting but not by PCR are to be expected.

We thank Mr B Gormley from the Department of Histopathology, Flinders Medical Centre, for providing us with paraffin wax embedded sections and Dr AH Chalmers for synthesisin the oligonucleotides. This study was funded by the National Health and Medical Research Council and by the Anti-Cancer Foundation of the Universities of South Australia.

1 Cleary ML, Chao J, Warnke R, Sklar J. Immunoglobulin gene rearrangement as a diagnostic criterion of B-cell lymphoma. Proc Natl Acad Sci USA 1984;81:593-7.

2 Trainor KJ, Brisco MJ, Story CJ, Morley AA. Monoclonality on B-lymphoproliferative disorders detected at the DNA level. Blood 1990;75:2220-2.

3 Story CJ, Morley AA, Turner DR, Seshadri R. Diagnostic use of immunoglobulin and T-cell receptor gene rearrangements in lymphoproliferative disease. Aust $N Z J$ Med 1987;17:1-8.

4 Brisco MJ, Tan LW, Orsborn A, Morley AA. Development of a highly sensitive assay, based on the polymerase chain reaction, for rare B-lymphocyte clones in a polyclonal population. Br J Haematol 1990;75:163-7.

5 Kabat EA, Wu TT, Reid-Miller M, Perry HM, Gottesman KS. Sequences of proteins of immunological interest. 4th edn. Washington, DC: US Department of Health and Human Services, 1987

6 Ravetch JV, Siebenlist U, Korsmeyer S, Waldmann T, Leder P. Structure of the human immunoglobulin $\mu$ locus: characterization of embryonic and rearranged $J$ and $D$ genes. Cell 1982;27:583-91.

7 Tonegawa S. Somatic generation of antibody diversity. Nature 1983;302:575-81. 